\title{
Biography: Daniel Cottam
}

\section{Daniel Cottam ${ }^{1}$ (D)}

Received: 8 June 2020 / Revised: 30 June 2020 / Accepted: 2 July 2020 / Published online: 15 July 2020

(C) Springer Science+Business Media, LLC, part of Springer Nature 2020

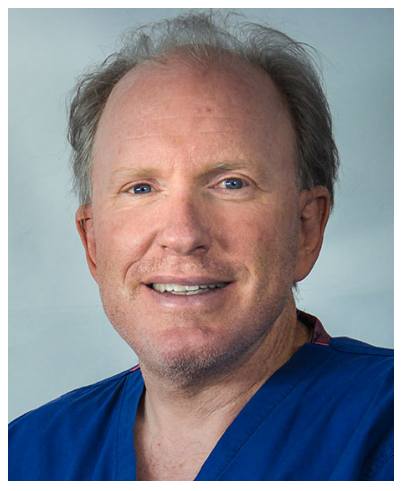

Daniel Cottam is wellknown in the bariatric community for his work pioneering SADI-S. However, he has also contributed to the fields of inflammation, sleeve gastrectomy, and oncology.

When Dr. Cottam began his residency, much was known about the associative relationship between obesity and many

types of cancer. However, there were no mechanistic pathways to explain why these associations occur. While doing his residency at the surgical department at Nassau University Medical Center with Gerald Shaftan MD, he had access to a flow cytometer. He along with his advisor, Peter Sheridan $\mathrm{Ph} . \mathrm{D}$, made a calculated guess that cancer in obesity must be due to dysfunctional immune privilege, which was widely talked about but not proven at that point. They chose to look at this from an apoptosis perspective and found that indeed obesity creates an environment which causes an upregulating of apoptosis markers on immunologic cell types resulted from chronic inflammation.

As residency finished, Dr. Cottam was accepted into a bariatric surgical fellowship with Dr. Philip Schauer. When Dr. Schauer saw his resume, he offered him the position saying "Dan I am only offering you a two-year fellowship because you need to spend a year to continue your research." While Dr. Cottam's first choice was a 1-year fellowship, his year of

Daniel Cottam

drdanielcottam@yahoo.com

1 Bariatric Medicine Institute, 1046 East 100 South, Salt Lake City, UT 84102, USA research was indeed a good advice, and during that time, he was able to expand on the idea of inflammation and cancer and became the first to propose a mechanism in the peerreviewed literature of how that occurs in specific cell lines. These findings were published in the Obesity Surgery.

One of the highlights of Dr. Cottam's life was performing the first gastric bypass in India. He had just finished fellowship, and his co fellow, Dr. Sunil Sharma, was trapped in India because of visa issues. He proposed that they could perform not only the first bypass but the first laparoscopic one as well. It was there in front of 250 surgeons with one monitor being black and white and one color with instruments that he borrowed from a hospital in Las Vegas that they did the first case on a patient who forgot to tell them about his history of pancreatitis. It did not go as smoothly as they wanted, but it must have been better than they thought since in that room were all the future founding fathers of Indian bariatric surgery.

Dr. Cottam then made an odd decision to pursue a career of academic medicine while in private practice in Las Vegas. There he was free to pursue his vision of research without departmental constraints. He was able to do this because his surgical partners, Dr. Barry Fisher and Dr. Jim Atkinson, appreciated the time and hard work it took to perform research and more importantly how research could direct clinical care.

While in Las Vegas, he was able to perform numerous studies on the benefits and drawbacks of lap band and gastric bypass as well as blinded trials of differing ways of performing the gastrojejunal anastomosis.

However, when the opportunity came to open his own practice in Salt Lake City, he did so. Starting off as an employed physician at the hospital in the first 3 years, he left hospital employment in 2011 to go into private practice. Ironically, when the constraints of hospital budgets were gone, he was able to dedicate even more time and resources to comparative outcomes. These studies included numerous papers on long-term complications associated with Roux limbs and new statistical models that more accurately predicted weight loss outcomes after RYGBP, sleeve gastrectomy, 
and SADI-S. These papers showed which patients benefited from each of the differing surgical options to maximize their weight loss with minimal complications. This research has resulted in over 250 articles and book chapters.

These intensive practice-based papers led him to the SADIS. Dr. Pernaute and Dr. Torres of Spain had published two papers, and Dr. Cottam felt that this was a significant improvement over Roux limbs. As with all innovations in any field, skepticism of this new approach was widespread (as it should be). Dr. Cottam teamed with Dr. Mitch Roslin from New York to begin an intensive publishing program to overcome loop bias using both practice's data in numerous comparative studies.

In the ensuing years, Dr. Cottam's relished meeting surgeons from all over the world who likewise were looking for new and better ways of doing bariatric surgery and would come to Utah and learn how to do the procedure and then team up with his practice to do research. Many of these people had never done research before, and it was a joy to work with them towards a common goal of seeing the SADI-S be accepted first by IFSO and then ASMBS.

Currently, Dr. Cottam works at the Bariatric Medicine Institute which he founded with his partners Dr. Christina Richards and Dr. Walter Medlin. They have been collectively working on the ability to do sleeve gastrectomy and the SADIS in an ambulatory surgical setting. In November 2019, Dr. Cottam was recognized for all of his innovative work by the ASMBS foundation with the ASMBS Surgical Innovation Award.

Through the years, many have noticed S. Cottam and A. Cottam on papers without a MD or Ph.D behind their names. These two individuals understand statistics in ways Dr.
Cottam knew he did not, and when he worked "the numbers" with them, they allowed many of the advancements with their comparative analysis. They are Dr. Cottam's sons, Samuel and Austin, and on their own approached their father after high school and volunteered to gather data and run statistics with him. Their ability to intuitively understand comparative analysis has allowed Dr. Cottam to process more data quickly than many other, better funded researchers. It has been a joy for him to work with them.

Dr. Cottam has been happily married to his wife, Amy, for 30 years and has 5 children. Austin is currently a third-year student at the University of Texas Southwestern Medical School. Samuel just graduated from the Brigham Young University in mathematics and is getting a master's degree in statistics. His three daughters, Naomi, Ruth, and Elsie, are still in primary school. When he is not operating inside, Dr. Cottam loves to be outside enjoying mountain biking, rafting, kayaking, back country skiing, and canyoneering.

\section{Compliance with Ethical Standards}

Conflict of Interest Dr. Cottam reports personal fees from the Metronic, outside the submitted work.

Ethical Approval This article does not contain any studies with human participants or animals performed by any of the authors.

Informed Consent Informed consent does not apply.

Publisher's Note Springer Nature remains neutral with regard to jurisdictional claims in published maps and institutional affiliations. 